\title{
Determinants of Child Health-Care Seeking among Mothers Attending Immunization Clinic at Urban Comprehensive Health Centre, Eleyele, Ile- Ife
}

\author{
Article by Victoria Adesola Ogungbemi \\ BSN-MSN, Texila American University, Nigeria \\ E-mail:vaogungbemi@gmail.com
}

\begin{abstract}
Health care seeking in terms of illness behavior refers to those activities undertaken by individuals in response to symptom experience. The patriarchal nature of Nigeria family system burdens the woman with childcare in addition to other responsibilities. Maternal response to child illness often determines the survival status, but the promptness of this response is determined by several factors both at individual and household level. This study explored the knowledge and factors affecting child health care seeking behaviour among mothers attending immunization clinic at Urban Comprehensive Health Centre, Eleyele, Ile-Ife.

This descriptive study selected two hundred respondents using convenience sampling technique. Structured questionnaire was used to elicit information from the respondents. Special package for social sciences was used to analyze the data collected for this study.

A major striking finding reveals that majority (64.3\%) of the mothers has poor knowledge and a larger proportion (82.6\%) with negative attitude towards child's health care seeking. The sociodemographic differential of mothers seeking health is also a significant finding. Majority of the mothers are on the lowest wealth quintile, earning less than 20,000 per month. This seems inadequate to seek quality health care service and might be responsible for their negative attitude. It is therefore necessary for all health-care providers to channel their effort towards increasing awareness campaign about the benefits of positive health care seeking. Women should be empowered in order to boost their economic status. Nurses should also play the advocacy role for free health services or highly subsidized health care expenses.
\end{abstract}

Keywords: Child, Determinants, Mothers, Health-Care, Seeking, Behaviour.

\section{Introduction}

Parents in all societies raise their children in a way that is generally compatible with the demands of their physical environment, socio-economic conditions, demographic characteristics, and the belief system that has been ingrained in their society. Variation in patterns of child rearing is associated with diversity in parent's control over these four dimensions of their environment. This suggests a dynamic interaction in which many factors contribute to the pattern of child care. Women are known and considered all over the world as the first providers of health care in the home. Mother's behaviour in seeking health either as a preventive or curative treatment is an important factor in determining child survivorship through the child's health and nutritional status and most especially against all forms of diseases, as well as through her own health.

Mothers in developing countries, however, often do not have sufficient knowledge of signs that their child's health is in danger, or of appropriate treatments, or access to appropriate health services. Palve and Sankhe (2016)Poor mothers are also more likely to live in remote areas, which can lead to delays in seeking care, and to fatalities.

There has been an anecdotal report that many children brought to the children emergency unit of OAUTHC were always brought in with complications which would have been prevented if their 
Texila International Journal of Nursing

Volume 2, Issue 2, Dec 2016

mothers had sought medical care on time. Some of these children even died, because their mothers did not bring them to the hospital on time.

Existing studies have shown that factors associated with a mother's care-seeking behaviors when faced with childhood illness are as follows: the mother's level of education, economic status, mother's age ethnicity, distance to the health care facility, the child's age, birth order of the child, child nutritional status, lack of recognition of the severity of the illness, the presence of diarrhea or respiratory disease, prior participation in health education, knowing a medical doctor, and the quality of the health care services provided

\section{Method}

This survey was conducted in an Urban Comprehensive Health Centre Ile-Ife. This centre is a subHospital unit of Obafemi Awolowo University Teaching Hospitals Complex Ile-Ife. It is located in Eleyele area in Ife Centre local Government Ile-Ife. Ile-Ife is an ancient town that is widely believed to be the cradle of the Yoruba race. The town is situated at about 80 kilometers east of Ibadan, 32 kilometers south of Ilesa and 64 kilometers north east of Ondo town. Urban comprehensive Health Center, Eleyele, Ile-Ife is a subsidiary part of Obafemi Awolowo University teaching Complex.

The descriptive survey research design was adopted for this survey. This is because the study is meant to collect a baseline data on health seeking behavior of mother to child immunization in UCHC, Eleyele, Ile-Ife. The most appropriate sampling technique for this survey is the grab/convenience sampling technique.

The quantitative data collected was analyzed using the SPSS (version 15) computer package. These descriptive statistics were presented using frequency tables and percentages.

\section{Results}

\section{Socio-demographic characteristics of the respondents}

Most of the respondents 75 (38.3\%) were between the age range of 20-25 years, 38 (19.4\%) were between 31-34 years, 27 (13.8\%) were between 26-30 years, 36-40 years were 17 (8.7\%), 11 (5.6\%) were between while $28(14.3 \%)$ did not respond to the question. This simply means most of the respondents were relatively young mothers, although almost all age categories were represented in the survey.

On marital status, majority of the respondents 191(974) were married and 05 (2.6) were divorced. This means that all the respondents were married women but with different status.

Still on Table 1, most of the respondents 169 (86.2\%) were Christians, 25 (12.8\%) were Muslims while $01(1.5 \%)$ each were either traditional worshiper or did not respond to the question. This means that most of the people that participated in this survey were Christian faith believers.

In respect to respondents ethnicity, about $123(62.8 \%)$ were Yoruba, $15(7.7 \%)$ came the other tribes 11 (5.6\%) were Igbo people while only 01(0.5\%) was Hausa and 46(23.5\%) did not answer the question. This means that Yoruba people participated mostly in this research. This is because the study location (Ile-Ife) is popularly called the cradle of Yoruba. The Table also shows that Ile-Ife is a city that accommodates people from different walks of life.

On educational qualification of the respondents, majority of the respondents 89 (45.4\%) hold HND or University degree, 52 (26.5\%) were secondary school leavers, 39 (19.9\%) had other qualification such as NCE, MBA and some medical certificates, 09 (4.6\%) have only primary school certificate while 07 (3.6\%) have no formal education. This means over $90.0 \%$ of the respondents were literate at different levels.

In respect to what respondents do for a living, majority of the respondents 69 (35.2\%) were white collar workers, 54 (27.6\%) were traders, 26 (13.3\%) were students, 19 of the respondents (9.7\%) were into business, 15 (7.7\%) were self-employed while 08 (4.1\%) were artisans and only $05(2.6 \%)$ did not respond to the question. This means that all the respondents engage in one form of thing or the other for their living but most of them were civil servants. 
Finally, on respondents income monthly, 80 (40.8\%) of the respondents earn between 5, 00020,000 each month, 23 (11.7\%) of them earn 65,000 and above every month, 20 (10.2\%) of the respondents earn 20,000-35,000 while 12 (6.0\%) earn between 35,000-50,000 while 59 (30.1\%) of them said No response. This means that all the response earn something at the end of each month to cater for their families but nobody earn less than 5,000 and above 65,000 each month depending on the business and their academic qualification. This is very pathetic because with the amount the respondents earn each month, it cannot cater for health care especially when they heave serious or chronic health condition.

\section{General factors influencing mothers health seeking behavior}

Quite a number of indicators used to measure factors that can influence mother's health seeking behavior for their children. for the first indicator, most of the respondents 134 (68.4\%) agree that health education received in immunization clinic affect mother's attitude towards health care seeking behavior, for the second indicator, 131 (66.8\%) agree mothers cannot solely make determination on health care seeking behavior, for third indicator, 99 (50.5\%) disagree that money is the determinant of one's attitude towards health seeking for my child during immunization, forth indicator, 114 (58.2\%) agree that closeness of health facility determine the type of behavior mothers demonstrate in health seeking for their child during immunization, for fifth indicator109 (55.6\%) of the respondents disagree with self-medication for their child, for the sixth indicator, 167 (85.7\%) agree that hospital protocol can be a discouragement for seeking health care and finally for this table, 168 (85.7\%) agree that hospital workers' attitude can be a discouragement for seeking health care. This means that mother's attitude to prompt or low health seeking for their child during illness is a determinant of quite a number of factors. Factors such as knowledge about sicknesses or illnesses that affect children and proximity to health centers can make mothers to be proactive to a quick attitude to seek health care services for their child. On the other hand factors such as inability of mothers to take decision on child's health, lack of money, hospital protocol and medical staff attitude (negative) are factors that can discourage mothers from seeking health care for their children on time. This is the situation most Nigerians mothers find themselves.

\section{Discussion}

The result of this study shows Yoruba dominance of mothers (62.8\%) attending immunization clinic at Urban Comprehensive Health Centre, Eleyele, Ile-Ife, this is due to the fact that Ile-Ife is a Yoruba town. Actually Ile-Ife is the cradle of the Yoruba tribe.

This study established that significant proportion (69.4\%) of the respondents heard about health care behavior from the hospital, however, only (7.7\%) visit hospital for health care service while majority (77.6\%) visit patent medicine store for health care services. This underscores the findings of Rahman (2000).

A proportion of $(40.8 \%)$ earn between the ranges of \#5,000 to \#20,000 monthly this seems inadequate to seek quality health care service and might be responsible for their negative attitude to health care seeking behavior; this is in consistent with the assertion of Seeramaredy et al (2006).

Furthermore, results from this study shows that majority of the respondent (64.3\%) have poor knowledge about health care seeking behavior, this might be responsible for the negative attitude observed in most of the respondents (82.6\%).

In consonance with Babar T. Shaikh and Juanitar Hatcher (2005), this study also shows that (66.8\%) of respondent agreed that mothers cannot solely make decision on health care seeking for self and child.

This study further shows that closeness to health facility as well as hospital workers' attitude toward patients are the main factor influencing mothers' attitude towards health care seeking behaviour which is in congruent with the work of Babar T. Shaikh and Juanitar Hatcher (2005). 


\section{Conclusion}

This study concludes that mother's attitude to prompt or low health seeking for their child during illness is a determinant of quite a number of factors. Factors such as knowledge about sicknesses or illnesses that affect children and proximity to health centers can make mothers to be proactive to a quick attitude to seek health care services for their child. On the other hand factors such as inability of mothers to take decision on child's health, lack of money, hospital protocol and medical staff attitude (negative) are factors that can discourage mothers from seeking health care for their children on time. This is the situation most Nigerians mothers find themselves

\section{Figures and tables}

\section{Socio-demographic characteristics of the respondents}

\begin{tabular}{|l|l|l|}
\hline Age Distribution & Frequency & Percentage \\
\hline 20-25 years & 75 & 38.3 \\
\hline 26-30 years & 27 & 13.8 \\
\hline 31-35 years & 38 & 19.4 \\
\hline 36-40 years & 17 & 8.7 \\
\hline 41 years and above & 11 & 5.6 \\
\hline No Response & 28 & 14.3 \\
\hline Total & $\mathbf{1 9 6}$ & $\mathbf{1 0 0 . 0}$ \\
\hline Marital Status & \multicolumn{1}{|l|}{} \\
\hline Married & 191 & 97.4 \\
\hline Divorce & 05 & 2.6 \\
\hline Total & $\mathbf{1 9 6}$ & $\mathbf{1 0 0 . 0}$ \\
\hline Religion & 169 & 86.2 \\
\hline Christianity & 25 & 12.8 \\
\hline Muslims & 01 & 1.5 \\
\hline Traditional & 01 & 1.5 \\
\hline No Response & $\mathbf{1 9 6}$ & $\mathbf{1 0 0 . 0}$ \\
\hline Total & 123 & 62.8 \\
\hline Ethnicity & 01 & 0.5 \\
\hline Yoruba & 11 & 5.6 \\
\hline Hausa & 15 & 7.7 \\
\hline Igbo & 46 & $\mathbf{1 0 0 . 0}$ \\
\hline Other tribes & $\mathbf{1 9 6}$ & \\
\hline No Response & & \\
\hline Total & \multicolumn{1}{|l|}{} \\
\hline
\end{tabular}

\begin{tabular}{|c|c|c|}
\hline \multirow{2}{*}{\multicolumn{3}{|c|}{$\begin{array}{l}\text { 4.1b Socio-Demographic } \\
\text { Respondents } \\
\text { Educational Qualification } \\
\end{array}$}} \\
\hline & & Educational Qualification \\
\hline No formal Education & 07 & 3.6 \\
\hline Primary School & 09 & 4.6 \\
\hline Secondary School & 52 & 26.5 \\
\hline HND/University Degree & 89 & 45.4 \\
\hline Other Qualification & 39 & 19.9 \\
\hline Total & 196 & $\mathbf{1 0 0 . 0}$ \\
\hline \multicolumn{3}{|c|}{ Respondents means of Livelihood } \\
\hline Civil Servant & 69 & 35.2 \\
\hline
\end{tabular}


Texila International Journal of Nursing Volume 2, Issue 2, Dec 2016

\begin{tabular}{|l|l|l|}
\hline Trader & 54 & 27.6 \\
\hline Artisan & 08 & 4.1 \\
\hline Business & 19 & 9.7 \\
\hline Students & 26 & 13.3 \\
\hline Self-Employed & 15 & 7.7 \\
\hline No Response & 05 & 2.6 \\
\hline Total & $\mathbf{1 9 6}$ & $\mathbf{1 0 0 . 0}$ \\
\hline Respondents monthly Earning & \multicolumn{2}{|l|}{} \\
\hline N5,000-N20,000 & 80 & 40.8 \\
\hline N20,000-N35,000 & 20 & 10.2 \\
\hline N35,000-N50,000 & 12 & 6.0 \\
\hline N50,000-N65,000 & 02 & 1.0 \\
\hline N65,000 above & 23 & 11.7 \\
\hline No Response & 59 & 30.1 \\
\hline Total & $\mathbf{1 9 6}$ & $\mathbf{1 0 0 . 0}$ \\
\hline
\end{tabular}




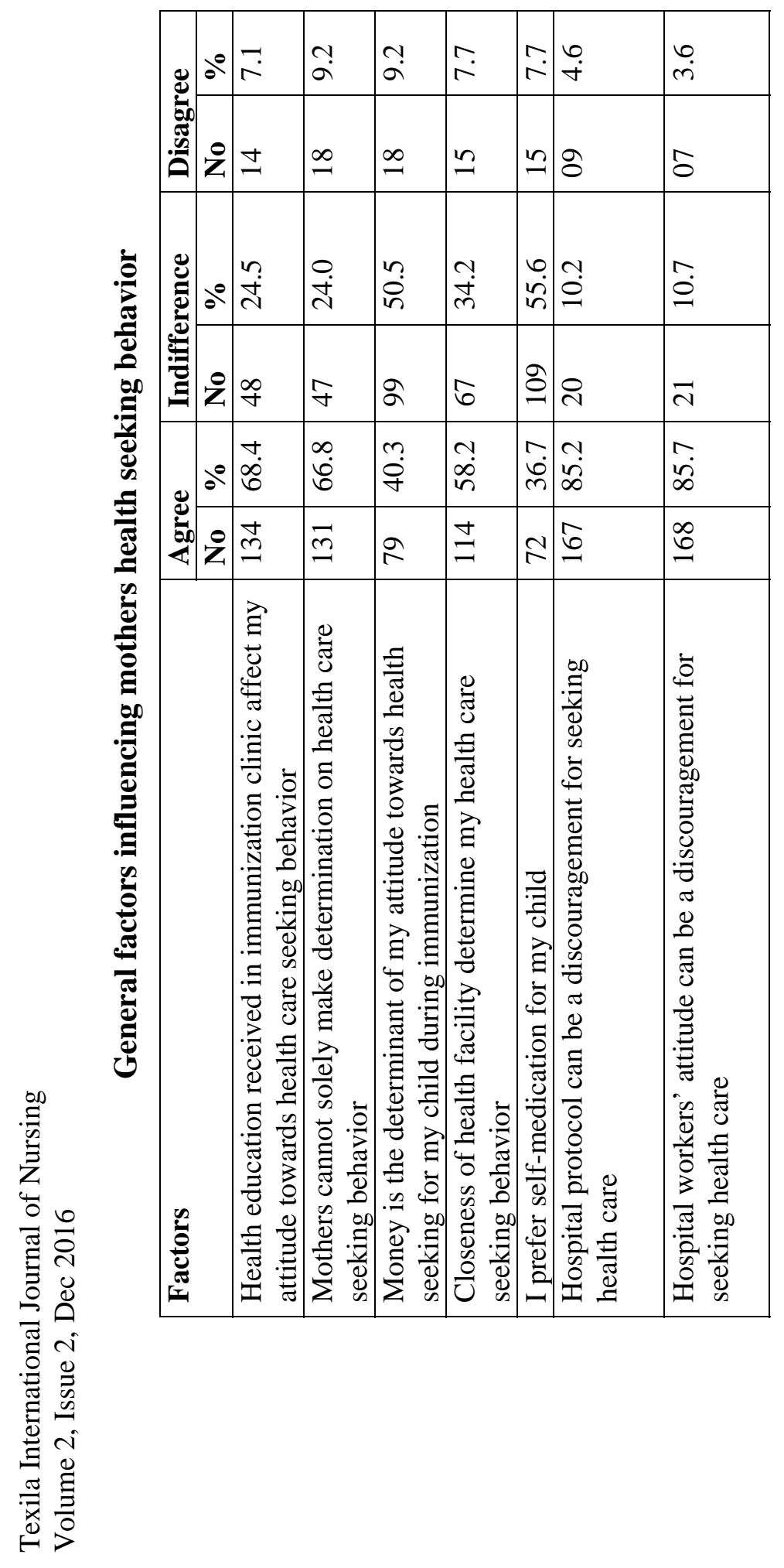




\section{References}

[1]. Adam B, Beck U and van Loon J Eds (2000) The Risk Society and Beyond Critical Issues for Social Theory Sage, London.

[2]. Ahmed, S Adams, A Chowdhury, M and Bhuiya, A (2000) Gender, socio-economic development and health-seeking behaviour in Bangladesh Social Science and Medicine 51(3). 361-371. Ahmed, S Chowdhury, M and Bhuiya, A (2001) Micro-Credit and emotional Well-Being: Experience of Poor Rural Women from Matlab, Bangladesh World Development 29(11). 1957-1966.

[3]. Ahmed, S Sobhan, F Islam, A and Barkat-e-Khuda (2001) Neonatal morbidity and care-seeking behaviour in rural Bangladesh Journal of Tropical Paediatrics 1 April 47(2). 98-105.

[4]. Babar T. Shaikh and Juanita Hatcher, (2005) Health seeking behaviour and health service utilization in Pakistan: challenging the policy makers. Journal of Public Health VoI. 27, No. 1, pp. 49-54. Published by Oxford University Press on behalf of Faculty of Public Health.

[5]. Campbell, C and Mzaidume, Z (2001) Grassroots participation, peer education, and HIV prevention by sex workers in South Africa American Journal of Public Health 91. 1978-1986

[6]. Dhesi, AS (2000) Social capital and community development Community Development Journal 35(3). July. 199-214

[7]. Jain, M., Nandan, D and Misra, S.K., (2006), Qualitative Assessment of Health Seeking Behaviour and Perceptions Regarding Quality of Health Care Services among Rural Community of District Agra. Indian Journal of Community Medicine Vol. 31

[8]. Lash, S and Urry, J (1994) Economies of Signs and Space Sage, London.

[9]. Narayan, D (1999) Bonds and Bridges: Social Capital and Poverty Poverty group, World Bank. July [10]. Palve, Shailesh and Lalit Sankhe(2016). "A Study to Assess Mothers' Health Seeking Behavior For Childhood Illnesses In An Urban Settlement In Maharashtra, India". Indian journall of Applied Research 6.3 (2016): 192-193. Print.

[11]. Olenja, J., (2003), Health Seeking Behaviour in Context. East African Medical Journal. On-line Available. [12]. Segall, M, Tipping, G, Dao, XV and Dao, LH (1999) Economic reform, poverty and equity in access to health care: case studies in Vietnam Research Report 34. IDS, Brighton.

[13]. Sreeramareddy, C.T., Shankar,R.P.; Sreekumaran1, B.V.; Subba, S.H.; Hari S Joshi and Uma Ramachandran (2006), Care seeking behaviour for childhood illness- a questionnaire survey in western Nepal. BMC International Health and Human Rights 2006, 6:7 http://www.biomedcentral.com/1472-698X/6/7

[14]. Tipping, G and Segall, M (1995) Health Care Seeking Behaviour in Developing Countries: an annotated bibliography and literature review Development Bibliography 12. Institute of Development Studies, Sussex University. 